Elsevier

\title{
Persistent cortisol non-suppression after clinical recovery predicts symptomatic relapse in unipolar depression
}

\author{
Gérard A. Charles ', Michel Schittecatte ${ }^{1}$, A. John Rush ${ }^{2}$, Michael Panzer ${ }^{3}$ and \\ Jean Wilmotte ${ }^{1}$ \\ 'Centre Hospitalier Vincent Van Gogh, Rue de l'Hopital 55, B-6030 Charleroi, Belgium, ' University of Texas Health Science Center, \\ Department of Psychiatry, Dallas, TX 75235, U.S.A. and ${ }^{3}$ University of Michigan Department of Psychiatry, \\ Ann Arbor, MI 48109, U.S.A.
}

(Received 17 June 1988)

(Revision received 21 March 1989)

(Accepted 11 April 1989)

\section{Summary}

We assessed the length and the quality of remission of 13 unipolar endogenous depressed patients, DST non-suppressors before treatment, in a 2-year prospective study. During this period, we recorded stressful life events. Persistent dexamethasone non-suppression, after treatment and complete clinical recovery, correlated highly with early clinical relapse. All six non-normalizers but only one normalizer were rehospitalized within the following 2 years for a major depressive relapse. Persistent DST non-suppression was unrelated to any impact of drug discontinuation, the occurrence of stressful life events or the length of illness-free intervals in the patient's prior course of illness. Persistent DST non-suppression appears to have significant prognostic value.

Key words: Dexamethasone suppression test; Treatment outcome; Unipolar depression; Life events

\section{Introduction}

Early escape of plasma cortisol the day following a 1-mg dexamethasone dose at midnight apparently identifies endogenous depression (melancholia) with a sensitivity ranging from 35 to $60 \%$ (Carroll, 1982). Dexamethasone non-suppression

Address for correspondence: Gérard A. Charles, MD, Centre Hospitalier Vincent Van Gogh, Rue de l'Hôpital 55, B-6030 Charleroi, Belgium. seems to be state-dependent as the dexamethasone suppression test (DST) normalizes in over $70 \%$ of the DST non-suppressors with clinical recovery and DST normalization usually occurs before complete symptomatic remission (Greden et al., 1983). Through different depressive episodes, the DST remains comparable for any single patient (Grunhaus et al., 1983). Further reversion of dexamethasone suppression to non-suppression apparently precedes clinical relapse by $1-3$ weeks (Holsboer et al., 1983). Several studies have postulated that persistent DST non-suppression in 
TABLE 1

STUDIES OF DST STATUS AND SYMPTOMATIC RELAPSE

\begin{tabular}{|c|c|c|c|c|c|}
\hline Authors & & $\begin{array}{l}\text { At discharge } \\
(n)\end{array}$ & $\begin{array}{l}\text { Poor outcome } \\
\text { (n) }\end{array}$ & Delay ${ }^{a}$ & Remarks \\
\hline $\begin{array}{c}\text { Goldberg } \\
(1980)\end{array}$ & $\begin{array}{l}(1) \\
(2)\end{array}$ & $\begin{array}{l}5 \\
5\end{array}$ & $\begin{array}{l}5 \\
0\end{array}$ & $\begin{array}{l}2-8 \\
7\end{array}$ & $\begin{array}{l}\text { Stopped meds after } \\
\text { one month; Non-sup- } \\
\text { pression } 7 \mu \mathrm{g} / \mathrm{dl}\end{array}$ \\
\hline $\begin{array}{l}\text { Greden et } \\
\text { al. (1980) }\end{array}$ & $\begin{array}{l}(1) \\
(2)\end{array}$ & $\begin{array}{l}4 \\
8\end{array}$ & $\begin{array}{l}4 \\
0\end{array}$ & $\begin{array}{l}6-8 \\
7-36\end{array}$ & $\begin{array}{l}\text { Retrospective study } \\
\text { Non-suppression } \\
6 \mu \mathrm{g} / \mathrm{dl}\end{array}$ \\
\hline $\begin{array}{l}\text { Papakostas } \\
\text { et al. } \\
(1981)\end{array}$ & $\begin{array}{l}(1) \\
(2)\end{array}$ & $\begin{array}{l}3 \\
5\end{array}$ & $\begin{array}{l}3 \\
0\end{array}$ & $\begin{array}{l}4-8 \\
1-9\end{array}$ & $\begin{array}{l}\text { Dexamethasone } 2 \mathrm{mg} \\
\text { Non-suppression } 7 \mu \mathrm{g} / \mathrm{dl} \\
\text { ECT }\end{array}$ \\
\hline $\begin{array}{l}\text { Coryell and } \\
\text { Zimmermann } \\
(1983)\end{array}$ & $\begin{array}{l}(1) \\
(2)\end{array}$ & $\begin{array}{l}7 \\
9\end{array}$ & $\begin{array}{l}2 \\
6\end{array}$ & $\begin{array}{c}\text { No info } \\
6\end{array}$ & $\begin{array}{l}\text { Normalizers: less } \\
\text { sustained recovery } \\
\text { ECT }\end{array}$ \\
\hline $\begin{array}{l}\text { Targum } \\
\text { (1983) }\end{array}$ & $\begin{array}{l}\text { (1) } \\
\text { (2) }\end{array}$ & $\begin{array}{r}6 \\
26\end{array}$ & $\begin{array}{l}5 \\
4\end{array}$ & $\begin{array}{c}\text { No info } \\
6\end{array}$ & \\
\hline $\begin{array}{l}\text { Yerevanian } \\
\text { et al. } \\
\text { (1983) }\end{array}$ & $\begin{array}{l}(1) \\
(2)\end{array}$ & $\begin{array}{l}8 \\
4\end{array}$ & $\begin{array}{l}8 \\
0\end{array}$ & $\begin{aligned} & 1-32 \\
\leq & 18\end{aligned}$ & $\begin{array}{l}\text { High rate of sui- } \\
\text { cide ( } 30 \%) \text { among } \\
\text { non-normalizers }\end{array}$ \\
\hline $\begin{array}{l}\text { Nemeroff and } \\
\text { Evans } \\
\text { (1984) }\end{array}$ & $\begin{array}{l}(1) \\
(2)\end{array}$ & $\begin{array}{r}4 \\
13\end{array}$ & $\begin{array}{l}4 \\
2\end{array}$ & $\begin{array}{l}2-16 \\
1-13\end{array}$ & \\
\hline $\begin{array}{l}\text { Targum } \\
\text { (1984) }\end{array}$ & $\begin{array}{l}(1) \\
(2)\end{array}$ & $\begin{array}{r}8 \\
25\end{array}$ & $\begin{array}{l}5 \\
4\end{array}$ & $\begin{array}{c}\text { No info } \\
6\end{array}$ & \\
\hline $\begin{array}{l}\text { Lipman } \\
\quad \text { et al. } \\
\quad(1986)\end{array}$ & $\begin{array}{l}(1) \\
(2)\end{array}$ & $\begin{array}{r}8 \\
11\end{array}$ & $\begin{array}{l}2 \\
9\end{array}$ & $\begin{array}{c}\text { No info } \\
6\end{array}$ & $\mathrm{ECT}$ \\
\hline $\begin{array}{l}\text { Mendlewicz } \\
\text { et at. (1986) }\end{array}$ & $\begin{array}{l}(1) \\
(2)\end{array}$ & $\begin{array}{r}9 \\
31\end{array}$ & $\begin{array}{l}2 \\
8\end{array}$ & $\begin{array}{c}\text { No info } \\
12\end{array}$ & ECT \\
\hline $\begin{array}{l}\text { Katona } \\
\text { et al. } \\
\text { (1987) }\end{array}$ & $\begin{array}{l}(1) \\
(2)\end{array}$ & $\begin{array}{l}3 \\
3\end{array}$ & $\begin{array}{l}2 \\
2\end{array}$ & $\begin{array}{c}\text { No info } \\
6\end{array}$ & ECT \\
\hline $\begin{array}{l}\text { Peselow et } \\
\text { al. (1987) }\end{array}$ & $\begin{array}{l}(1) \\
(2)\end{array}$ & $\begin{array}{r}9 \\
20\end{array}$ & $\begin{array}{l}4 \\
6\end{array}$ & $\begin{array}{c}\text { No info } \\
6\end{array}$ & \\
\hline $\begin{array}{l}\text { Schweitzer } \\
\text { et al. (1987) }\end{array}$ & $\begin{array}{l}(1) \\
(2)\end{array}$ & $\begin{array}{r}7 \\
15\end{array}$ & $\begin{array}{l}5 \\
1\end{array}$ & $\begin{array}{c}\text { No info } \\
3\end{array}$ & $\mathrm{ECT}$ \\
\hline
\end{tabular}

a Delay indicates the delay of relapse (in weeks) for the non-normalizers (1) and the delay of survey (in months) for the normalizers (2).

b No info indicates that these non-normalizers relapsed at unspecified times after discharge, within the same survey period as for normalizers.

clinically improved patients indicates a poor prognosis relative to normalization of DST status. These and other studies are summarized in Table 1.

We selected only paticnts who were DST nonsuppressors before treatment. Follow-up data for both normalizers and non-normalizers were required for a study to be included. We disregarded cases whose clinical recovery was insufficient to allow discharge as they might better be regarded as treatment failures. Several studies concur that failure to normalize the DST with clinical recovery is predictive of a higher risk of early relapse. Greden et al. (1980) found that among pharmacologically treated paticnts, all four non-normalizers but none of eight normalizers had a poor outcome at follow-up.

A number of groups have used concomitant electroconvulsive therapy (ECT) and pharmacotherapy. Schweitzer and collaborators (1987) 
obtained similar results, with five of seven persistent non-suppressors but only one of 15 normalizers relapsing. In contrast, Lipman et al. (1986) found the opposite: nine of 11 normalizers compared to two of eight persistent non-suppressors were treatment failures within 6 months. A paper by Katona and others (1987) revealed no predictive value one way or the other for subsequent relapse.

Overall, 13 studies have followed 384 initial DST non-suppressors, among whom 153 (40.3\%) failed to normalize the DST with clinical improvement. Of the 231 who did normalize their DST, only $46(19.9 \%)$ relapsed compared to 59 of 156 (31.8\%) who failed to normalize their DST (Fisher's exact test: $P<0.0001)$. Relapse occurred between 0.5 and 18 months post discharge.

Occurrence of stressful life events has been implicated in relapse of depression. Paykel (1979) found that repetitive stress can exacerbate endogenous depression. Lloyd (1980) reviewed eight controlled studies, seven of which found a significant correlation between life events (mostly loss of immediate family members or close friends) and subsequent depression. More recently, however, Brown et al. (1987) used a combination of contextual methods and 'matching' of events to characteristics of the 400 women in the study to demonstrate 'the major importance of long-term severe threatening life events in provoking caseness of depression'.

The present study evaluated clinical factors that might relate to continuing DST non-suppression following clinical recovery, including occurrence of stressful events, type of treatment, and a number of descriptive patient characteristics. Persistent non-suppression vs. normalization and medication status were tested as predictors for clinical relapse. We included only endogenous depressives with a prior history of complete clinical remission between previous episodes, or patients who were suffering their first depressive episode. We excluded chronic depression.

\section{Patients and methods}

\section{Patients}

From October 1980 through December 1981, we identified 13 inpatients from roughly 500 inpa- tients consecutively admitted to the Department of Psychiatry, Civil Hospital, Charleroi (Belgium). The patients completed a follow-up period consisting of 2 years on a monthly basis. All patients met Research Diagnostic Criteria (RDC) (Spitzer et al., 1978) for primary major unipolar depression, definite endogenous subtype, as well as DSM-III criteria for major depression with melancholic features (American Psychiatric Association, 1980). Bipolar patients were excluded. We also excluded patients with alcoholism, medical disorders, obesity, and those taking oral contraceptives or drugs that induce liver enzymes (Carroll et al., 1981).

Clinical assessment was based on the SADS-L structured interview (Spitzer and Endicott, 1978). Nine of the 13 patients suffered from recurrent depressive episodes. The mean number of episodes was $4.8(\mathrm{SD}=3.2)$ and ranged from two to 11 episodes. Only DST non-suppressors, i.e., patients with 4 p.m. plasma cortisol of $5 \mu \mathrm{g} / \mathrm{dl}$ or greater, as measured $17 \mathrm{~h}$ after the ingestion of $1 \mathrm{mg}$ dexamethasone, were included (Charles et al., 1981). Written informed consent was obtained from patients.

\section{Methods}

Patients were hospitalized for at least 10 days and were drug-free for at least 15 days before the first 1-mg overnight DST (time 1). The DST methodology and cortisol determinations have been previously described (Charles et al., 1981). The severity of depressive symptoms was assessed with the 21-item Hamilton Rating Scale for depression (HRS) (Hamilton, 1960). Before discharge, patients received a second DST (time 2) as described above, while taking either amitriptyline or desipraminc.

Patients received either amitriptyline or desipramine (not randomized). Treatment began after the initial assessment (time 1) procedures were completed. Treatment was selected and conducted independent of and blind to these ratings. All patients and treating physicians were blind to DST and rating scales results. The physicians judged symptomatic recovery and made decisions to discharge based only on their own clinical judgment. However, clinical improvement that was sufficient to merit discharge was routinely associated with at least a $50 \%$ reduction in the initial 
HRS score and in all cases with an end of hospitalization HRS score of 12 or less. The medication ingested was recorded for the survey period, but antidepressant plasma levels were not measured. Antidepressant medications only are reported here. None of the other drugs taken by the patients are known to influence the DST (Carroll et al., 1981; Amsterdam et al., 1981) and none was taken later than 1 month prior to time 3 evaluation.

Relapse was defined as a new episode of major depression, requiring readmission. Between 3 and 18 months following hospital discharge, seven patients were thus rehospitalized. A second psychiatric evaluation and, after a 15-day drug-free wash-out period, a third DST (time 3) were conducted. Within 2 years, the remaining six patients, without relapse, underwent a third DST and HRS.

Life events were assessed at time 3. This information was corroborated by the monthly clinical interviews by the primary physicians. For the period between times 2 and 3 , the number of stressful events was counted based on the list of events (Paykel et al., 1971). Their subjective importance was assessed according to Monroe's methodology (1982).

\section{Statistics}

Welch's $t$-test (WtT) and paired $t$-test (PtT) were used. Fisher's exact test (FET) was used for the $2 \times 2$ comparisons in which one of the expected values was 5 or less. The chi-square test was used for the other categorical comparisons. All $P$ s were 2-tailed. The results are expressed as the means, standard deviations and ranges.

\section{Results}

Table 2 displays the results for the entire sample. At the end of the first hospitalization, all 13 patients were clinically recovered (HRS time 2: $7.1(3.4) ; 3-12$ ) but only seven (54\%) normalized the DST (i.e., became DST suppressors). The six patients who remained non-suppressors at the end of hospitalization were rehospitalized within the following 2 years for a depressive relapse which

TABLE 2

SAMPI.F. CHARACTFRISTICS

\begin{tabular}{|c|c|c|c|c|c|c|c|c|c|}
\hline$\overline{\text { Age } / \operatorname{sex}}$ & $\begin{array}{l}\text { No. } \\
\text { epi }\end{array}$ & $\begin{array}{l}\text { Inter } \\
\text { epi }\end{array}$ & $\begin{array}{l}\text { Time } 1 \\
\text { CORT/HRS }\end{array}$ & $\begin{array}{l}\text { Time } 2 \\
\text { CORT/HRS }\end{array}$ & $\begin{array}{l}\text { Time } 3 \\
\text { CORT/IIRS/month }\end{array}$ & $\begin{array}{l}\mathrm{T} 2-\mathrm{T} 3 \\
\text { (months) }\end{array}$ & $\begin{array}{l}\text { Treatment } \\
\text { Duration }\end{array}$ & $\begin{array}{l}\text { No. life } \\
\text { events }\end{array}$ & $\begin{array}{l}\text { T2-LE } \\
\text { (months) }\end{array}$ \\
\hline$* 54 / \mathrm{M}$ & 2 & 48 & $8.5 / 42$ & $9.5 / 11$ & $7.0 / 39 / \mathrm{Feb}$ & 3 & AMI 3 & 0 & $\mathrm{NA}$ \\
\hline$* 50 / \mathrm{F}$ & 4 & 18 & $7.0 / 40$ & $5.0 / 6$ & $5.0 / 36 / \mathrm{Apr}$ & 3 & AMI 3 & 31 & 2 \\
\hline$* 66 / \mathrm{F}$ & 8 & 34 & $8.0 / 39$ & $5.0 / 4$ & $9.5 / 38 / \mathrm{Apr}$ & 5 & AMI 5 & 0 & NA \\
\hline$* 67 / \mathrm{M}$ & 6 & 26 & $6.0 / 41$ & $5.0 / 12$ & $6.0 / 35 / \mathrm{Oct}$ & 6 & DMI 6 & 0 & NA \\
\hline$* 31 / \mathrm{F}$ & NA & NA & $8.0 / 21$ & $6.0 / 8$ & $6.5 / 28 / \mathrm{Dec}$ & 10 & DMI 10 & 0 & NA \\
\hline$* 36 / \mathrm{F}$ & NA & NA & $5.0 / 24$ & $2.0 / 4$ & $5.5 / 29 /$ May & 12 & AMI 12 & 0 & NA \\
\hline$* 45 / \mathrm{F}$ & NA & $\mathrm{NA}$ & $6.0 / 22$ & $5.0 / 7$ & $3.5 / 25 /$ Sept & 18 & DMI 9 & 0 & NA \\
\hline $33 / F$ & NA & NA & $10.5 / 38$ & $2.0 / 10$ & $2.5 / 8 / \mathrm{NA}$ & 19 & AMI 12 & 16 & 2 \\
\hline $60 / \mathrm{F}$ & 11 & 25 & $14.0 / 38$ & $2.0 / 3$ & $3.5 / 8 / \mathrm{NA}$ & 20 & DMI 20 & 0 & NA \\
\hline $60 / \mathrm{M}$ & 6 & 46 & $5.0 / 40$ & $3.0 / 12$ & $2.0 / 11 / \mathrm{NA}$ & 22 & DMI 8 & 15 & 10 \\
\hline $59 / \mathrm{F}$ & 2 & 60 & $7.5 / 17$ & $2.0 / 3$ & $2.5 / 8 / \mathrm{NA}$ & 24 & AMI 24 & 4 & 20 \\
\hline $53 / \mathrm{F}$ & 2 & 30 & $14.0 / 34$ & $2.0 / 4$ & $4.0 / 10 / \mathrm{NA}$ & 25 & AMI 10 & 5 & 22 \\
\hline $41 / F$ & 2 & 30 & $9.5 / 34$ & $2.0 / 9$ & $2.0 / 4 / \mathrm{NA}$ & 26 & AMI 6 & 33 & 11 \\
\hline
\end{tabular}

No. epi indicates number of previous episodes.

Inter epi indicates mean duration in months between previous episodes.

Treatment: DMI indicates desipramine; AMI indicates amitriptyline.

Duration indicates duration in months between time 2 and end of antidepressant treatment.

No. life events indicates number counted following Paykel et al. (1971).

T2-LE indicates months between time 2 and occurrence of life event.

Time $3 /$ month indicates month of relapse.

* Relapses; NA, not applicable; CORT, 4 p.m. post-dexamethasone cortisol ( $\mu \mathrm{g} / \mathrm{d} 1$ ); HRS, 21-item Hamilton Rating Scale score. 
once again met RDC for major depression, endogenous subtype. Out of the seven DST normalizers at time 2 , only one was rehospitalized (after 12 months). DST non-suppression in this patient at time $3(5.5 \mu \mathrm{g} / \mathrm{dl})$ was comparable to his postdexamethasone cortisol at time $1(5.0 \mu \mathrm{g} / \mathrm{dl})$. The difference in the number of relapsing patients among the seven normalizers $(n=1)$ and the six non-normalizers $(n=6)$ reached a level of $P=$ 0.005 (FET). For the seven relapsers, HRS at time 3 (32.8 (5.4); 25-39) did not differ from HRS at time 1 (32.7 (9.7); 24-42) $(\mathrm{PtT}=0.03 ; d f=6$; $P=\mathrm{NS})$. Six of the seven who relapsed were still DST non-suppressors at the time of relapse (cortisol at time 3: $6.8(1.8) ; 5.0-9.5 \mu \mathrm{g} / \mathrm{dl}$ ), while one of the relapsers was a suppressor (cortisol at time 3: $3.5 \mu \mathrm{g} / \mathrm{dl}$ ). There were no significant differences between the normalizers and non-normalizers at time 2 for type of treatment (five of seven normalizers and three of six non-normalizers received amitriptyline; FET $P=0.528$ ). The two populations were comparable for age (48.9 (11.9) for normalizers vs. 52.2 (13.6) for non-normalizers; $\mathrm{Wt}^{\top} \mathrm{T}=0.46 ; P=\mathrm{NS}$ ), sex ratio (six of seven normalizers and four of six non-normalizers were female; FET $P=0.552$ ) and age at the onset of illness (normalizers 37.5 (6.9) vs. non-normalizers $42.0(7.0) ; \mathrm{WtT}=1.1 ; P=\mathrm{NS}$ ). The HRS scores at time 2 for the six non-normalizers $(8.00$ (3.03)) did not significantly differ from those of the normalizers $(6.42(3.77))(t=0.831 ; d f=10$; $P=\mathrm{NS})$. There were no differences between the relapsers and non-relapsers at time 1 either in post-dexamethasone cortisol levels (relapsers 6.9 (1.3) vs. non-relapsers $10.0(3.5) ; t=2.19 ; d f=11$; $P=0.051)$ or in HRS scores (relapsers $32.7(9.7)$ vs. non-relapsers $33.5(8.4) ; t=0.15 ; d f=11 ; P=$ 0.881 ). For the patients suffering from recurrent illness (five normalizers and four non-normalizers), no difference was observed in the number of previous episodes (normalizers 4.6 (4.0) vs. nonnormalizers $5.0(2.6) ; \mathrm{WtT}=0.18 ; P=\mathrm{NS})$ or in the mean time between episodes (normalizers 38.2 (14.0) months vs. non-normalizers 31.5 (12.7); $\mathrm{WtT}=0.73 ; P=\mathrm{NS}$ ).

Among the seven normalizers, five experienced stressful events within the following 2 years $(2-22$ months) before the time 3 re-evaluation, although none of these five relapsed. The one normalizer who did relapse did not report any stressful events. Only one of the six non-normalizers who relapsed reported a stressful event, which occurred 1 month before relapse.

The difference between the two groups in the number of patients who experienced any kind of stressful life events did not reach statistical significance (five of seven normalizers vs. one of six non-normalizers; FET $P=0.103$ ). The low incidence of reported life stresses and the sample size preclude discussion of any relationship between life stresses and clinical relapse. However, in this sample, stressful life events do not relate to the subsequent course of illness.

Medication status did not seem to influence relapse. No significant difference between relapsers and non-relapsers with regard to medication status at time 3 was found (relapsers: six of seven on drug compared to non-relapsers: two of six; FET $P=0.3099$ ). Four of the six normalizers stopped taking medication 7-20 months before time 3 evaluation, and none relapsed. The two normalizers who were still taking their drug at time 3 were withdrawn for 15 days in order to perform the DST at time 3, and neither exhibited any recurrence of symptomatology. One patient who failed to normalize his DST in the meanwhile stopped taking medication $y$ months before relapse. Five non-normalizers and one normalizer were still on medication when they relapsed.

\section{Discussion}

These data indicate that clinical relapse over the short term (3-18 months) more often occurred in those DST non-suppressors who failed to normalize their DST at the time of clinical recovery than in those who normalized their DST. The time between hospital discharge and relapse was shorter than the usual euthymic time period between previous episodes. Stressful life events did not seem to account for relapse. A number of patients who normalized their DST at time 2 experienced significant and in some cases severe life stresses but failed to relapse. The state-dependent relationship between persistent non-suppression and likelihood of relapse, as well as the relationship between suppression and a more durable recovery, is indicated by these data. Finally, as previously re- 
ported (Grunhaus et al., 1983), patients' DST statuses are reproducible across different episodes of depression. That is, a patient who is a non-suppressor in one episode is likely to fail to suppress in the following episode.

As stated above, our finding that persistent non-suppression is a risk factor for early relapse supports the results of Schweitzer et al. (1987). Other recent reports, however, find no value no DST normalization vs. persistent non-suppression for predicting relapse. Katona et al. (1987) found no significant difference between these two groups of patients treated with ECT and medication. Mendlewicz et al. (1986) had similar results. Peselow et al. (1987) had a non-significant trend (six of 20 normalizers relapsed vs. four of nine persistent non-suppressors). Varying criteria for recovery and relapse may partially account for the contradiction. While our patients showed a decrease in HRS scores to 12 or less with treatment which represented a $50 \%$ or more improvement, Katona et al. required a final HRS of 6 or less, and Mendlewicz et al. required an HRS improvement of $70 \%$ or more. If Schweitzer et al. (1987) are correct in suggesting that persistent non-suppressors may have persistent hypothalamic-pituitaryadrenal (HPA) axis dysfunction despite clinical improvement, then more stringent improvement criteria might exclude some partially treated cases, thus making the two groups appear more similar in prognosis. Relapse criteria could also help explain the different results. Mendlewicz et al. defined relapse as depression meeting RDC criteria for major depressive disorder. We considered only depression necessitating readmission. It is possible that the two patient groups differ prognostically only in regard to more severe symptoms; this would explain why our study using stricter relapse criteria achieved significance while others may not.

Neither of these could explain the results of Lipman et al. (1986), who found that persistent non-suppressors had a better prognosis at 6-month follow-up. In that retrospective study, however, the authors did not know what treatment the patients received between discharge and relapse. Similarly, Coryell and Zimmerman (1983) had results contradicting ours in the same way, but did not report intervening treatment between dis- charge and follow-up. Thus, different treatment between suppressors and non-suppressors could account for the results of these two studies, while we have documented that treatment did not differ between our patient groups. We admit, however, that we did not measure antidepressant blood levels to further verify this. Moreover, we did assess the compliance of the patients, followed on a regular monthly basis, to their medication.

One strength of the present study is the followup period of 2 years, which is longer than most others. The use of extended follow-up periods in future studies may add to the weight of evidence supporting the utility of DST results in predicting prognosis.

Another factor that needs to be considered is ECT vs. pharmacological treatment. From studies done thus far, no clear pattern is evident regarding the effect of treatment modality on predicting delayed outcome based on DST results. However, two studies (Coppen et al., 1985; Devanand et al., 1987) show that the DST has different predictive values in immediate outcome depending on whether ECT or drug therapy was used. This needs to be explored in future studies.

The trend (even non-significant) for the nonnormalizers to exhibit a slightly higher HRS score at recovery (time 2) compared to normalizers goes along with observations by Greden et al. (1980) and might reflect a persistent dysregulation or partial treatment response. The high frequency of relapses among the non-normalizers could be explained as a consequence of having an illness that is poorly or only partially treated with available antidepressant techniques. Antidepressant drugs might increase motor activity and lead to significant clinical improvement, but fail to fully convert the underlying pathophysiology of the illness. It is understandable that a partially effective antidepressant drug (too short-timed, infratherapeutic plasma levels, low local brain concentrations or not specific enough) might increase motor activity without modifying the endocrine perturbances (e.g., DST non-suppression) which could secondarily lead to clinical relapse (Holsboer et al., 1983). A clinical example of this hypothesized dissociation between clinical and HPA status is to be found at the beginning of most antidepressant drug therapy. Patients usually show psychomotor 
improvement within the first 5 days (Ey et al., 1974). However, the DST normalizes around 2-3 weeks, just before internal feelings and the general mood improve (Greden et al., 1983).

The implication is that persistent non-suppressors need to be treated more aggressively. This would be at odds with the results of Goldberg (1980) and the present study that discontinuation of treatment does not precipitate relapse. Our normalizers did not relapse despite discontinuation, while the persistent non-suppressors relapsed in the face of ongoing treatment. However, the possibility certainly exists that better maintenance treatment (antidepressant blood levels, different drug choice or modalities) in future studies could show that long-term treatment of persistent nonsuppressors prevents relapse while treatment of normalizers could be more safely discontinued.

The other goal of this study was to examine the possible role of life events in precipitating relapse. In our sample, stressful events did not precipitate a recurrence of major depressive symptoms nor did they reverse a normalized DST. This agrees with Saleem's observation (1984) that DST nonsuppression in depression is more related to an endogenous substrate for the illness than to anxiety or stress. Lesser and co-workers (1984) were unable to discriminate situational depression from depression without precipitating events by DST non-suppression in endogenously ill patients. Mendlewicz et al. (1986) found no correlation between relapse and life events (except bereavement among immediate family and close friends) among 24 unipolar and 16 bipolar endogenous patients. Four of 10 relapsers and four of 30 non-relapsers experienced life events. Certainly, methodological issues assume major importance in studying life events and depression.

Lack of social support could be a bias in studying relapse in depressive patients. In our sample, we retrospectively check that no patient lost any social support during the survey period.

Another factor that might be responsible for abnormal DST results is the altered dexamethasone kinetics in depressed patients (Maguire et al., 1987).

Lowy and Meltzer (1987) recently stated that 'simultaneous measurement of serum dexamethasone and cortisol levels appears to be necessary for the appropriate evaluation of DST results'

The best way to assess the very low dexamethasone concentration during a DST seems to be a microliquid chromatography-mass spectrometry method. This is not yet available on a clinical routine basis. However, DST has been shown to be reproducible within a single episode (Charles et al., 1982) and across hospitalizations (Grunhaus et al., 1983). Moreover, Carson et al. (1988) demonstrated that patients with major depressive disorders had less suppressibility of cortisol to the same plasma dexamethasone concentrations than controls. Differences in dexamethasone metabolism might explain different DST statuses in major depressive disorders. A genuine reduced sensitivity of cortisol to dexamethasone still points to an abnormality of the feedback mechanism of the HPA in some depressed patients. The normalization after treatment of this abnormality and the DST reversion back to suppression might lead to a sustained recovery in those normalizers, whereas the non-normalizers might keep a higher cortisol/ dexamethasone ratio and reach a less complete recovery.

This study provides preliminary results. Replication with a longer survey period to better account for the spontaneous course of illness, with assessment of antidepressant and dexamethasone plasma levels and with a greater number of endogenous patients, as well as a control group of reactive depressives, is needed. However, the present findings argue for the prognostic value of persistent DST non-suppression unrelated to any impact of stressful life events.

\section{References}

American Psychiatric Association (1980) Diagnostic and Statistical Manual of Mental Disorders (DSM-III). APA. Washington, DC.

Amsterdam, J.D.. Winokur, A. and Caroff, S. (1981) Effect of tricyclic antidepressants on the dexamethasone suppression test. Am. J. Psychiatry 138, 1245-1246.

Brown, G.W., Bifulco, A. and Harris, T.O. (1987) Life events, vulnerability and onset of depression: some refinements. Br. J. Psychiatry 150, 30-42.

Carroll, B.J. (1982) The dexamethasone suppression test for melancholia. Br. J. Psychiatry 140, 292-304.

Carroll, B.J., Feinberg, M., Greden, J.F., Tarika, J., Albala, A.A., Haskett. R.F., James, N.M., Kronfol, Z., Lohr, N., Steiner, M., de Vigne, J.P. and Young, E. (1981) A specific 
laboratory test for the diagnosis of melancholia. Arch. Gen Psychiatry 38, 15-22.

Carson, S.W., Halbreich, U., Ching, M.Y., Asnis, G. and Goldstein, S. (1988) Cortisol suppression per nanogram per milliliter of plasma dexamethasone in depressive and normal subjects. Biol. Psychiatry 24, 569-577.

Charles, G., Vandewalle, J., Meunier, J.C., Wilmotte, J., Noel, G., Fossoul, C., Martens, Y. and Mendlewicz, J. (1981) Plasma and urinary cortisol levels after dexamethasone in affective disorders. J. Affect Disord. 3, 397-406.

Charles, G., Wilmotte, J., Quenon, M. and Mendlewicz, J. (1982) Reproducibility of the dexamethasone suppression test in depression. Biol. Psychiatry 17, 7.

Coppen, A., Milln, P., Harwood, J. and Wood, K. (1985) Does the dexamethasone suppression test predict antidepressant treatment success? Br. J. Psychiatry 146, 294-296.

Coryell, W. and Zimmerman, M. (1983) The DST and ECT outcome: a six months follow-up. Biol. Psychiatry 18, 21-27.

Devanand, D.P., Decina, P., Sackeim, H.A., Hopkins, N., Novacenko, H. and Malitz, S. (1987) Serial dexamethasone suppression tests in initial suppressors and nonsuppressors treated with electroconvulsive therapy. Biol. Psychiatry 22, $463-472$

Ey, H., Bernard, P. and Brisset, C. (1974) Manuel de Psychiatrie. Masson, Paris.

Goldberg, I.K. (1980) DST in depression and response to treatment. Lancet ii, 92

Greden, J.F., Albala, A.A., Haskett, R.F., James, N.M., Goodman, L., Steiner, M. and Carroll, B.J. (1980) Nomalization of dexamethasone suppression test: a laboratory index of recovery from endogenous depression. Biol. Psychiatry 15. $449-458$

Greden, J.F., Gardner, R., King, D., Grunhaus, L., Carroll, B.J. and Kronfol, Z. (1983) DST in antidepressant treatment of melancholia; the process of normalization and test-retest reproducibility. Arch. Gen. Psychiatry 40, $493-500$

Grunhaus, L., Greden, J.F. and Carroll, B.J. (1983) The dexamethasone suppression test in repeated hospitalizations. Biol. Psychiatry 18, 1497-1502.

Hamilton, M. (1960) A rating scale for depression. J. Neurol. Neurosurg. Psychiatry 23, 56-62.

Holsboer, F. (1983) Prediction of clinical course by DST response in depressed patients. Physiological and clinical construct validity of the DST. Pharmacopsychiatry 16 $186-191$

Holsboer, F., Steiger, A. and Maier, W. (1983) Four cases of reversion to abnormal DST as indicator of clinical relapse: a preliminary report. Biol. Psychiatry 18, 911-916.

Katona, C.L.E., Aldridge, C.R., Roth, M. and Hyde, J. (1987) The dexamethasone suppression test and prediction of outcome in patients receiving ECT. Br. J. Psychiatry 150, 315-318.

Lesser, I.M., Rubin, R.T. and Finder, E. (1984) Situational depression and the dexamethasone suppression test. Psychoneuroendocrinology $8,441-445$.
Lipman, R.S., Uffner, W., Schwalb, N., Ravetz, R., Licf, B., Lévy, S. and Levenberg. D. (1986) Dexamethasone suppression test as a predictor of response to electroconvulsive therapy. II. Six month follow-up. Convuls. Ther. 2, 161-167.

Lloyd, C. (1980) Life events and depressive disorder reviewed II. Events as predisposing factors. Arch. Gen. Psychiatry $37,541-548$

Lowy, M.T. and Meltzer, H.Y. (1987) Dexamethasone bioavailability: implications for DST research. Biol. Psychiatry $22,373-385$

Maguire, K.P., Schweitzer, I., Biddle, N., Bridge, S. and Tiller, J.W.G. (1987) The dexamethasone suppression test: importance of dexamethasone concentrations. Biol. Psychiatry $22,957-967$.

Mendlewicz, J., Charon, F. and Linkowski, P. (1986) Life events and the dexamethasone suppression test in affective illness. J. Affect Disord. 10, 203-206.

Monroe, S.M. (1982) Life events assessment: current practices, emerging trends. Clin. Psychol. Rev. 2, 435-453.

Nemeroff, C.B. and Evans, D.L. (1984) Correlation between the dexamethasone suppression test in depressed patients and clinical response. Am. J. Psychiatry 141, 247-249.

Papakostas, Y., Fink, M., Lee. J., Irwin. P. and Johnson. L. (1981) Neuroendocrine measures in psychiatric patients: course and outcome with ECT. Psychiatr. Res. 4, 55-64.

Paykel, E.S. (1979) Causal relationship between clinical depression and life events. In: J.E. Barrett, R.M. Rose and G.L. Klerman, (Eds.), Stress and Mental Disorder. Raven Press, New York, NY

Paykel, E.S., Prusoff, B.A. and Uhlenhuth, E.H. (1971) Scaling of life events. Arch. Gen. Psychiatry 25, 340-347.

Peselow, E.D., Baxter, N., Fieve, R.R. and Barouche, F. (1987) The dexamethasone suppression test as a monitor of clinical recovery. Am. J. Psychiatry 144, 30-35.

Saleem. P.T. (1984) DST in depressive illness: its relation to anxiety symptoms. Br. J. Psychiatry $144,181-184$.

Schweitzer. I., Maguire. K.P.. Tiller. J.W.G., Biddle. N. and Davies, B. (1987) Prediction of outcome in depressed patients by weekly monitoring with the dexamethasone suppression test. Br. J. Psychiatry 151, 780784.

Spitzer, R.L. and Endicott, J. (1978) Schedule for Affective Disorders and Schizophrenia: Life-time Version. New York State Psychiatry Institute, New York, NY.

Spitzer, R.L., Endicott, J. and Robins, E. (1978) Research Diagnostic Criteria: rationale and reliability. Arch. Gen. Psychiatry 35. 773-782.

Targum, S.D. (1983) The application of serial neuroendocrine challenge studies in the management of depressive disorder. Biol. Psychiatry 18, 3-19.

Targum, S.D. (1984) Persistent neuroendocrine dysregulation in major depressive disorder: a marker for early relapse. Biol. Psychiatry 19, 305-318.

Yerevanian, B.I., Olafsdottir, H., Milanese, E., Russotto, J., Mallon, P., Baciewicz, G. and Sagi, E. (1983) Normalization of the DST at discharge from hospital: its prognostic value. J. Affect. Disord. 5, 191-197. 